\title{
Temporal distribution of tuberculosis in the State of Amazonas, Brazil
}

\author{
Marlucia da Silva Garrido[1],[2],[3],[4], Samira Bührer-Sékula ${ }^{[1],[5],}$ Alexandra Brito de Souza[1],[2], \\ Rajendranath Ramasawmy ${ }^{[1],[6], ~ P a t r i ́ c i a ~ d e ~ L i m a ~ Q u i n c o ́[1],[2], ~ R o s s i c l e i a ~ L i n s ~ M o n t e ~}{ }^{[1],}$ \\ Lucilaide Oliveira Santos ${ }^{[1],[2],}$ Tomás Maria Perez-Porcuna[2],[7], \\ Flor Ernestina Martinez-Espínosa[1],[8], Valéria Saraceni[1],[9] \\ and Marcelo Cordeiro-Santos ${ }^{[1],[2],[6]}$
}

\begin{abstract}
[1]. Departamento de Ensino e Pós-Graduação, Fundação de Medicina Tropical Dr. Heitor Vieira Dourado, Manaus, AM. [2]. Programa de Pós-Graduação em Medicina Tropical, Universidade do Estado do Amazonas Universidade do Estado do Amazonas, Manaus, AM. [3]. Departamento de Vigilância Epidemiológica, Fundação de Vigilância em Saúde do Amazonas, Manaus, AM. [4]. Secretaria Municipal de Saúde, Prefeitura Municipal de Manaus, Manaus, AM. [5]. Instituto de Patologia Tropical e Saúde Pública, Universidade Federal de Goiás, Goiânia, GO. [6]. Faculdade de Medicina, Universidade Nilton Lins, Manaus, AM. [7]. Departament of Public Health, Mútua Terrassa Research Foundation, University of Barcelona, Catalunya, Spain. [8]. Instituto Leonidas and Maria Deane, Fundação Oswaldo Cruz, Manaus, AM. [9]. Secretaria Municipal de Saúde do Rio de Janeiro, Prefeitura Municipal do Rio de Janeiro, Rio de Janeiro, RJ.
\end{abstract}

\begin{abstract}
Tuberculosis (TB) is one of the infectious diseases that contributes most to the morbidity and mortality of millions of people worldwide. Brazil is one of 22 countries that accounts for $80 \%$ of the tuberculosis global burden. The highest incidence rates in Brazil occur in the States of Amazonas and Rio de Janeiro. The aim of this study was to describe the temporal distribution of TB in the State of Amazonas. Between 2001 and 2011, 28,198 cases of tuberculosis were reported in Amazonas, distributed among 62 municipalities, with the capital Manaus reporting the highest (68.7\%) concentration of cases. Tuberculosis was more prevalent among males (59.3\%) aged 15 to 34 years old (45.5\%), whose race/color was predominantly pardo $(64.7 \%)$ and who had pulmonary TB $(84.3 \%)$. During this period, 81 cases of multidrug-resistant TB were registered, of which the highest concentration was reported from 2008 onward $(p=0.002)$. The municipalities with the largest numbers of indigenous individuals affected were São Gabriel da Cachoeira (93\%), Itamarati (78.1\%), and Santa Isabel do Rio Negro (70.1\%). The future outlook for this region includes strengthening the TB control at the primary care level, by expanding diagnostic capabilities, access to treatment, research projects developed in collaboration with the Dr. Heitor Vieira Dourado Tropical Medicine Foundation [Fundação de Medicina Tropical Dr. Heitor Vieira Dourado (FMT-HVD)] and financing institutions, such as the project for the expansion of the Clinical Research Center and the creation of a hospital ward for individuals with transmissible respiratory diseases, including TB.
\end{abstract}

Keywords: Tuberculosis. Epidemiology. Temporal distribution.

\section{INTRODUCTION}

Tuberculosis (TB) is one of the infectious diseases that contributes most to the morbidity and mortality of millions of people worldwide ${ }^{(1)}$. The development of the disease depends on factors associated with the causative bacillus ${ }^{(2)}$, the host, and socioeconomic factors. The cell wall of the bacillus is the most important virulence factor, allowing TB to survive in a latent state for decades. Some conditions, such as immunosuppression, an age of less than 4 years, malnutrition, and alcohol and drug abuse, increase the risks of developing $\mathrm{TB}^{(3)(4)}$. Socioeconomic factors, such as low income, lack of sanitation, living in close

Corresponding author: Dr. Marcelo Cordeiro-Santos. FMT-HVD. Av. Pedro Teixeira 25, 69040-000 Manaus, AM, Brasil.

Phone: 5592 9119-9199

e-mail: marcelocordeiro.br@gmail.com

Received 10 March 2014

Accepted 5 August 2014 quarters, and environments with poor ventilation, also increase the opportunities for exposure to the bacillus and consequent illness ${ }^{(5)}$. Poor public health or weakened TB control programs can also contribute to the maintenance of the disease ${ }^{(()}$. Studies have also demonstrated that poverty and low socioeconomic status are associated with poorer treatment outcomes for $\mathrm{TB}^{(7)}$.

According to the World Health Organization (WHO), there were an estimated 8.6 million new TB cases in 2012, $13 \%$ of which was estimated to be coinfected with human immunodeficiency virus (HIV), and 1.3 million deaths were reported due to $\mathrm{TB}^{(8)}$. Brazil is one1 of 22 countries that account for $80 \%$ of the TB disease burden worldwide, with an annual average of 70,000 new cases distributed among 27 states. The highest incidence rates have been registered in the States of Amazonas and Rio de Janeiro ${ }^{(9)}$.

The State of Amazonas, which is located in the northern region of Brazil, has a territory of $1,570,745.680 \mathrm{~km}^{2}$ that is divided into 62 municipalities, and it had an estimated 
population of 3,483,985 inhabitants in 2011, 52\% of which lived in the capital, Manaus. The population density in the capital is 158 inhabitants $/ \mathrm{km}^{2}$ whereas the state has an overall population density ${ }^{(10)}$ of 2.2 inhabitants $/ \mathrm{km}^{2}$.

Cases of TB have been registered in the Amazonian population since the late nineteenth century, at which time the disease was the second leading cause of death in the population $^{(11)}$. In 2012, data from the Information System for Notifiable Diseases [Sistema de Informação de Agravos de Notificação (SINAN)] showed that the incidence rate of TB in Amazonas was 68.3/100,000 inhabitants, which is very high when compared to Brazil's national average incidence rate of 36.1/100,000 inhabitants'. From 2001 to 2011, there were 28,198 registered cases of TB in the State of Amazonas, distributed among the 62 municipalities. The capital had the highest (68.7\%) number of cases, followed by the municipalities of Manacapuru, Tabatinga, Itacoatiara, and Tefé. The overall distribution of both new and retreatment (relapse and return after abandoning treatment) TB cases is shown in Table 1.

The temporal distribution analysis of the entire period showed that TB was more prevalent in males $(59.3 \%)$, individuals between the ages of 15 and 34 years of age (45.5\%), individuals whose race/skin color was predominantly parda (64.7\%), given the huge interracial miscegenation with the indigenous people, and individuals who had not completed elementary education (56.6\%). There were 1,929 registered cases of indigenous individuals who were residents of the municipalities that have a predominantly indigenous population, such as São Gabriel da Cachoeira (93\% of the registered cases were in indigenous individuals), Itamarati (78.1\%), and Santa Isabel do Rio Negro (70.1\%). The pulmonary form of the disease was evident in $84.3 \%$ of cases. Sputum smear microscopy was performed for diagnosis in $92.1 \%$ of individuals over the age of 15 years. Mycobacterium tuberculosis cultures were performed for $7.7 \%$ of new cases and $21.4 \%$ of retreatment cases. HIV tests were performed in $25.6 \%$ of cases, with a positivity of $6.5 \%$ among new registered cases. As for the outcomes of the cases reported from 2001 to 2011, the cure rate among new smearpositive pulmonary TB cases was $73.1 \%$, and the treatment dropout rate was $10.4 \%$. The directly observed treatment (DOT) rate increased from $1.4 \%$ in 2001 to $56.5 \%$ in 2011 .

All trends were evaluated using simple linear regression, in order to assess the direction of the slope, upward, downward or stable. Linear regression model fitness was assessed by plotting the regression line, by examining the residuals and by the use of Pearson's correlation coefficient. There was a positive trend toward performing sputum cultures in new cases, increasing from $3.9 \%$ in 2001 to $19.8 \%$ in 2011 (p $=0.004)$. Similarly, there was an increase in performing cultures in retreatment cases, from $4.8 \%$ in 2001 to $53.4 \%$ in $2011(p=0.001)$. HIV testing for new cases increased from $2.2 \%$ in 2001 to $51.2 \%$ in $2011(\mathrm{p}<0.001)$, which was accompanied by a significant increase from $2.2 \%$ to $11.2 \%(p<0.001)$ in the proportion of TB/HIV co-infections identified during the study period. The cure rate of new smear-positive pulmonary TB cases showed a non-significant decreasing trend, from $81.2 \%$ in 2001 to $73.1 \%$
TABLE 1 - The distribution of new and retreatment cases of tuberculosis in the State of Amazonas from 2001 to 2011.

\begin{tabular}{cccc}
\hline Year & New cases & Retreatment & Total \\
\hline 2001 & 2,274 & 57 & 2,331 \\
2002 & 2,106 & 174 & 2,280 \\
2003 & 2,035 & 334 & 2,369 \\
2004 & 2,135 & 422 & 2,557 \\
2005 & 2,085 & 400 & 2,485 \\
2006 & 2,168 & 341 & 2,509 \\
2007 & 2,261 & 479 & 2,740 \\
2008 & 2,271 & 501 & 2,772 \\
2009 & 2,278 & 398 & 2,676 \\
2010 & 2,325 & 441 & 2,766 \\
2011 & 2,196 & 495 & 2,691 \\
\hline
\end{tabular}

Source: Brazil's Information System for Notifiable Diseases (Sistema de Informação de Agravos de Notificação (SINAN-TB), Department of Information for the Unified Health System (Departamento de Informática do Sistema Único de Saúde) (DATASUS).

in $2011(\mathrm{p}=0.244)$. The treatment dropout rate remained stable, at approximately 10\%, from 2001 to $2011(\mathrm{p}=0.572)$ (Table 2).

Tuberculosis/human immunodeficiency virus (TB/HIV) coinfected carriers received priority monitoring at the specialized assistance service for HIV/AIDS at the Dr. Heitor Vieira Dourado Tropical Medicine Foundation [Fundação de Medicina Tropical Dr. Heitor Vieira Dourado (FMT-HVD)] in Manaus. The outcome rates for TB/HIV co-infection cases each year at the FMT-HVD are shown in Table 3. The outcome rates of this group during the study period included a $52.4 \%$ cure rate, a $12.8 \%$ dropout rate, and a $21.9 \%$ death rate. Compared to the overall rates during the study period, HIV-positive patients had a lower cure rate $(\mathrm{p}<0.001)$, and both a higher TB death rate $(\mathrm{p}<0.001)$ and treatment dropout rate $(\mathrm{p}=0.028)$.

The incidence rate of TB in the State of Amazonas had a general downward trend but remained high throughout the analyzed period $(p=0.031)$ (Figure 1). In 2011, the Amazonas TB incidence rate was $62.3 / 100,000$ inhabitants $^{(9)}$, with a greater incidence in the municipalities of Atalaia do Norte $(135.1 / 100,000)$, Manaus $(87.7 / 100,000)$ and São Gabriel da Cachoeira (62.3/100,000).

The municipalities with higher numbers of registered cases among indigenous individuals included São Gabriel da Cachoeira (93\%), Itamarati (78.1\%), and Santa Isabel do Rio Negro (70.1\%).

The mortality rate of patients with TB as the underlying cause of death, as reported by the Mortality Information System [Sistema de Informações sobre Mortalidade (SIM)], had an oscillating behavior, with a slight downward trend between 2001 and 2004, followed by a period of fluctuation between 2.8 and 3.9 deaths/100,000 individuals until $2011(\mathrm{p}=0.861)$ (Figure 1). 


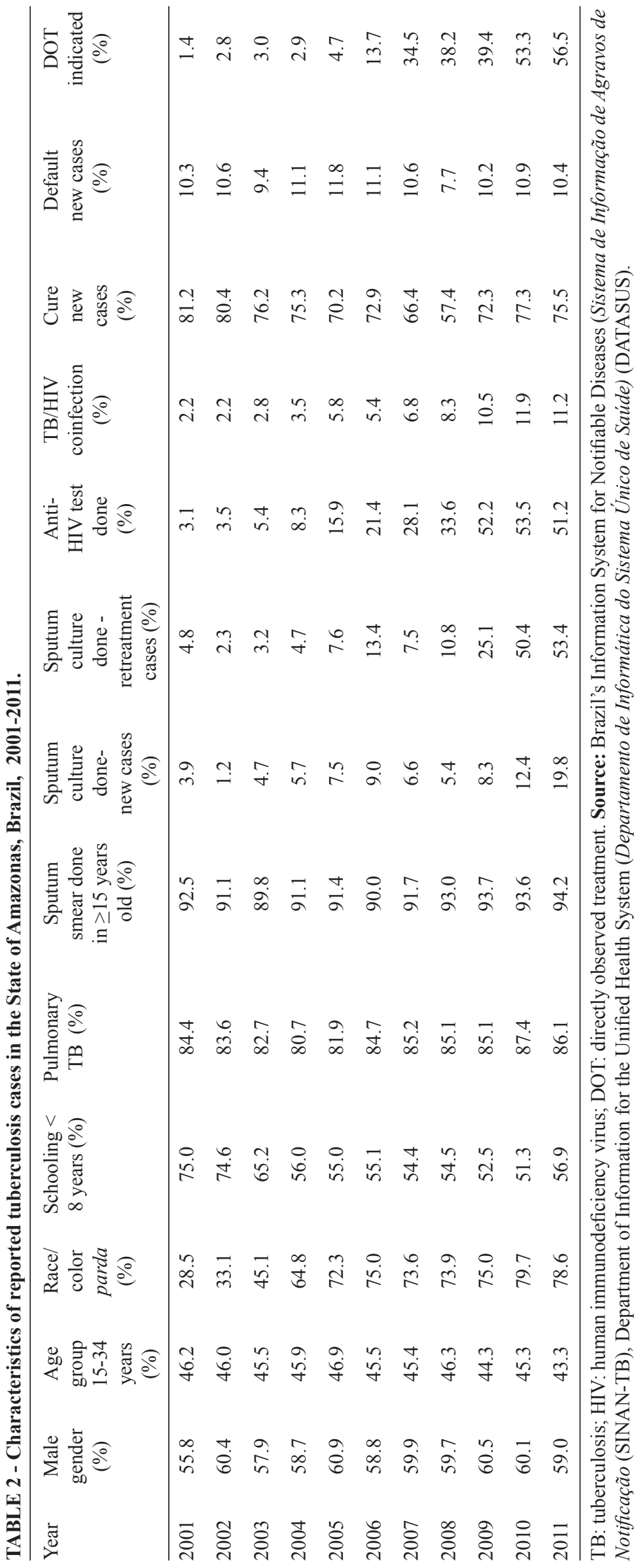

There were 81 confirmed cases of multidrugresistant-tuberculosis (MDR-TB) that were resistant to rifampicin and isoniazid during the study period, with the largest number of cases appearing in 2008. The annual increasing trend in the number of cases of MDR-TB was statistically significant $(\mathrm{p}=0.002)$ during the study period (Figure 2$)$. The rise in the number of MDR-TB cases is derived from the increase in the availability of sputum culture in the State of Amazonas.

Overall, the incidence rate of TB in Brazil has been steadily decreasing ${ }^{(12)}$, whereas in the State of Amazonas, there has only been a slight decrease; therefore, the State of Amazonas remains as 1 of 2 states with the highest incidence rates in Brazil. The highest incidence rate tends to alternate between the States of Amazonas and Rio de Janeiro ${ }^{(9)}$. Within Amazonas, there are regions with very high incidences, as noted in a study conducted among the indigenous population in the Alto Rio Negro (AM) region, which revealed that the incidence rate was $273 / 100,000$ inhabitants and that the mortality rate was $13.2 / 100,000$, well above the state averages ${ }^{(13)}$.

The TB mortality rate remained stable over the study period, although it was well above the national mortality rate and below the mortality rate observed in the State of Rio de Janeiro ${ }^{(9)}$. Both the relative and absolute number of TB deaths in Brazil decreased between 2001 and $2010^{(12)}$. However, in a study that examined the underreporting of tuberculosis in the SIM in Brazil, by comparing it to the SINAN, the percentage of unreported deaths in the country was $39.4 \%$, and in Amazonas, the percentage was $36.9 \%{ }^{(14)}$, suggesting a much greater mortality burden than has been reported for the state.

One additional concern regarding TB mortality in Amazonas is the people living with human immunodeficiency virus/acquired immunodeficienysyndrome (HIV/AIDS). A study conducted by the FMT-HVD implicated TB as the underlying cause of death in $28 \%$ of cases that went to autopsy $^{(15)}$, reinforcing the hypothesis that TB is one of the most important causes of death in this population. In the City of Rio de Janeiro, a study using secondary data demonstrated that between 1996 and 2005, 9\% of deaths among individuals living with HIV/AIDS were related to $\mathrm{TB}^{(16)}$. In São Paulo, Casseb et al ${ }^{(17)}$. reported a 10 -year survival rate of $75 \%$ following diagnosis for patients who were TB/HIV-positive, compared to a survival rate of $96 \%$ for patients from the same cohort who did not have TB $(\mathrm{p}=0.03)^{(17)}$.

For diagnostic etiology, we observed that in the State of Amazonas, there was still a high use of sputum smear microscopy to diagnose pulmonary tuberculosis, remaining above $90 \%$. However, the sensitivity of sputum smear microscopy in HIV patients is low; 


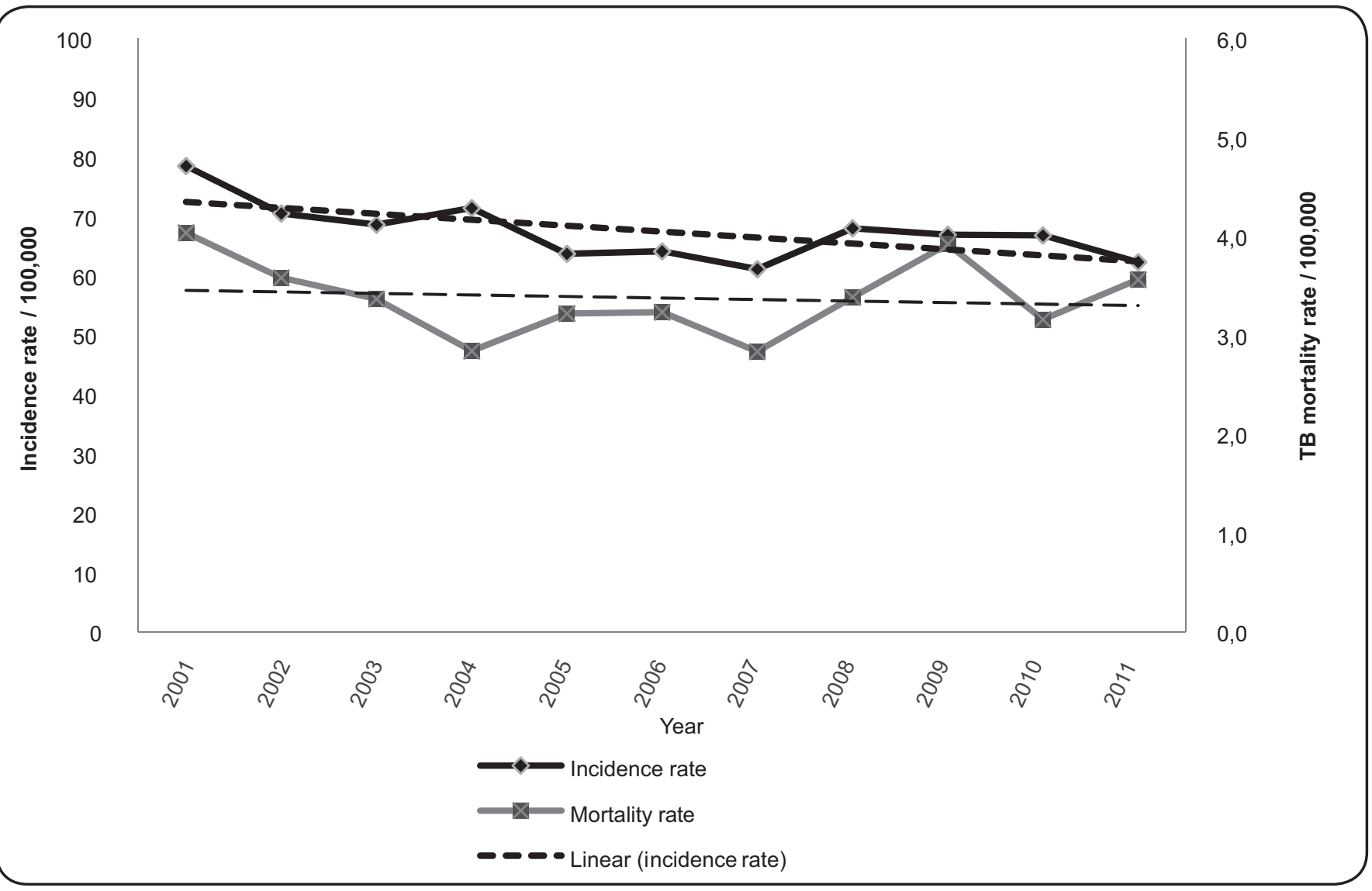

FIGURE 1 - Incidence and mortality rates of tuberculosis in the State of Amazonas, Brazil, 2001-2011. Source: Brazil's Information System for Notifiable Diseases (Sistema de Informação de Agravos de Notificação (SINAN-TB), Department of Information for the Unified Health System (Departamento de Informática do Sistema Único de Saúde) (DATASUS). TB: tuberculosis.

TABLE 3 - Monitoring the outcomes of TB/HIV co-infection cases at the Dr. Heitor Vieira Dourado Tropical Medicine Foundation, Manaus, Amazonas, Brazil, 2001-2011.

\begin{tabular}{lccc}
\hline Year & Cure $(\%)$ & Dropout $(\%)$ & TB death $(\%)^{*}$ \\
\hline 2001 & 34.1 & 19.5 & 43.9 \\
2002 & 40.0 & 14.0 & 26.0 \\
2003 & 53.6 & 7.1 & 33.9 \\
2004 & 47.2 & 11.2 & 34.8 \\
2005 & 34.8 & 34.8 & 26.8 \\
2006 & 47.4 & 19.3 & 8.8 \\
2007 & 55.1 & 9.5 & 21.8 \\
2008 & 57.3 & 8.7 & 8.7 \\
2009 & 52.5 & 13.8 & 16.1 \\
2010 & 53.8 & 9.8 & 13.1 \\
2011 & 62.3 & 8.1 & 6.9 \\
\hline
\end{tabular}

TB: tuberculosis; HIV: human immunodeficiency virus. Source: Brazil's Information System for Notifiable Diseases (Sistema de Informação de Agravos de Notificação (SINAN-TB), Department of Information for the Unified Health System (Departamento de Informática do Sistema Único de Saúde) (DATASUS). *From 2001 to 2006, there was no separation between TB deaths and deaths resulting from other causes in the SINAN-TB records. moreover, additional and time-consuming tests are needed for the early diagnosis of drug resistance. Quincó et al. ${ }^{(18)}$ showed that the addition of a polycarbonate membrane filtration technique increased the sensitivity of sputum smear microscopy in HIV-infected patients at the FMT-HVD, achieving $61.9 \%$ in the HIV-positive group and $81.8 \%$ in the HIV-negative cases.

A study on the roll-out of Xpert MTB/RIF®, performed in the Cities of Manaus and Rio de Janeiro, showed a preliminary increase of approximately $34 \%$ in the diagnosis of pulmonary $\mathrm{TB}^{(19)}$. Based on this study, the National Commission on Incorporation of Technologies [Comissão Nacional de Incorporação de Tecnologias no SUS (CONITEC)] approved the use of Xpert MTB/RIF® for the diagnosis of TB and the detection of rifampin resistance within the Unified Health System [Sistema Único de Saúde (SUS)] in Brazil ${ }^{(20)}$. The transition to Xpert MTB/RIF® represents an improvement in the diagnostic capability; in addition to providing results in approximately 2 hours and identifying rifampicin resistance, which is considered a strong predictor of MDR-TB, the test provides faster and more accurate results. However, it is still necessary to perform monthly sputum smear microscopy, cultures, and antibiotic sensitivity testing for other drugs as controls because the new test does not serve these purposes. 


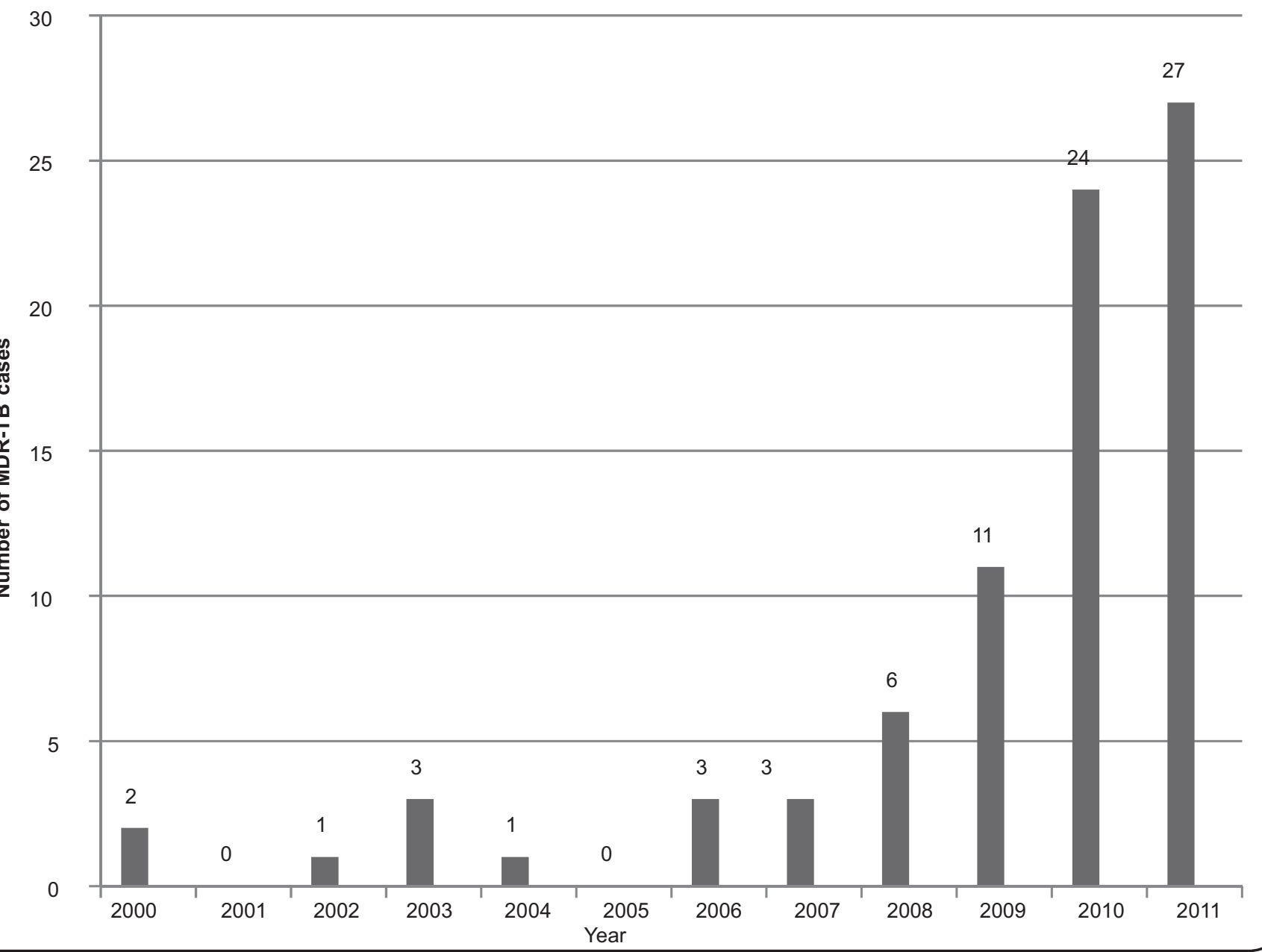

FIGURE 2 - Distribution of multidrug-resistant-tuberculosis (MDR-TB) cases according to the year of diagnosis in the State of Amazonas, 2001-2011. Source: Multidrug Resistant TB system [Sistema de Vigilância Epidemiológica para tubérculo multirresistente (TBMR/MS)]

The TB treatment dropout rate has several implications for disease control, such as disease persistence in individuals and in the community, a greater risk of developing MDR-TB, and the maintenance of TB indicators at undesirable levels because the cure rate is not increasing. As observed during this study period, treatment dropout rates remained stable, at approximately $10 \%$, in Amazonas. Garrido et al. ${ }^{(21)}$ previously reported treatment dropout, HIV positivity, alcoholism, low educational level, and the presence of other comorbidities as risk factors associated with TB treatment dropout in Amazonas. This group also reported that advanced age and DOT were protective factors ${ }^{(22)}$.

\section{FUTURE PERSPECTIVES}

Reducing TB morbidity and mortality in Amazonas, the state with the largest geographical area in the country, is a major challenge because of the obstacles that are unique to the Amazon region, such as the large territorial dispersion of the population and a low population density but with registered TB cases in all municipalities. Long distances make access to diagnosis and treatment services more difficult, frequently depending on the transport of biological samples from one municipality to another or the transport of individuals to the capital for specialized care. Decentralizing TB diagnosis and providing treatment in primary care services in all the state municipalities is one of the current priorities. One of the functions of the Family Health Strategy [Estratégia Saúde da Família (ESF)] is to provide care for TB patients, beginning at clinical suspicion and continuing through referral for diagnostic confirmation, monitoring confirmed cases via supervised treatment, and collecting monthly control sputum smear microscopy samples ${ }^{(22)}$.

However, the ESF coverage in the state only reaches approximately $50 \%$ of the population ${ }^{(23)}$. Considering the territorial dimensions and the dispersal of the disease throughout the state, additional strategies are needed to increase the diagnostic capability, especially in hard to reach populations (indigenous and riverine), HIV-positive individuals, and children $^{(18)(24)}$. In addition, increasing the cure rate, reducing the treatment dropout rates, and increasing the involvement of all healthcare professionals, including ESF teams, epidemiologists, microscopists, indigenous health workers, and community leaders, is needed in the efforts to control TB. 
The rural laboratory located in Tabatinga, AM is an example of a decentralized laboratory that can have a positive impact in the vast rural area ${ }^{(25)}$. The initiative to create a computerized laboratory results system from the Central Public Health Laboratories [Laboratórios Centrais de Saúde Pública (LACEN)], the Laboratory Environment Manager [Gerenciador de Ambiente Laboratorial (GAL)], is currently being implemented, which can expedite the transmission of results to places far from the capital ${ }^{(26)}$. There is still the question of diagnostics, and the incorporation of the Xpert MTB/RIF ${ }^{\circledR}$ system for routine laboratory monitoring in some municipalities may assist in diagnosing difficult cases, increasing the detection rate of TB cases, and facilitating the diagnosis of MDR-TB. Still, there is an urgent need to expand the diagnostic network and develop culture methods and tests that are more sensitive, accurate, and rapid that can be used in locations with scarce resources and that are difficult to reach.

Another exciting prospect for TB control in the Amazon is an expansion project by the Clinical Research Center [Centro de Pesquisa Clínica (CPC)] at the FMT-HVD. This project will create a hospitalization area for individuals with transmissible respiratory diseases, including TB, with isolation beds and a multidisciplinary team that will allow for increased research and provide expertise to aid in defining the strategic actions needed to control the disease.

The involvement of civil society in controlling TB is an important advance, as with the recent creation of the State Committee for the Control of Tuberculosis in State of Amazonas [(Comitê Estadual de Controle da Tuberculose do Amazonas CECTA) $]^{(27)}$. All Amazonian municipalities will be encouraged to create a municipal committee to provide greater visibility to the problem and to establish partnerships between government and civil society to identify effective actions in controlling the disease. Improvements in the diagnostic capacity will aid in detecting cases, but this measure alone will not change the TB situation in the State of Amazonas. Strengthening the TB control activities in all municipalities will also be necessary, including an emphasis on identifying active cases, examining contacts, and completing DOT.

\section{CONFLICT OF INTEREST}

The authors declare that there is no conflict of interest.

\section{FINANCIAL SUPPORT}

We would like to thank the Foundation for Research Support of the State of Amazonas [Fundação de Amparo à Pesquisa do Estado do Amazonas (FAPEAM)] and the National Council for Scientific and Technological Development [Conselho Nacional de Desenvolvimento Cientifico e Tecnológico (CNPq)] for their support.

\section{REFERENCES}

1. Ahmad S. Pathogenesis, immunology, and diagnosis of latent Mycobacterium tuberculosis infection. Clin Dev Immunol 2011; 2011:ID814943.

2. Dannenberg Jr AM. Immunopathogenesis of pulmonary tuberculosis. Hosp Pract (Off Ed) 1993; 28:51-58.
3. Jensen PA. Where should infection control programs for tuberculosis begin? Int J Tuberc Lung Dis 2005; 9:825.

4. Lawn SD, Zumla AI. Tuberculosis. Lancet 2011; 378:57-72.

5. Rasanathan K, Sivasankara Kurup A, Jaramillo E, Lonnronth $\mathrm{K}$. The social determinants of health: key to global tuberculosis control. Int J Tuberc Lung Dis 2011; 15 (suppl II):30-36.

6. Lonnronth K, Jaramillo E, Willams B, Dye C, Raviglione M. Tuberculosis: the role of risk factors and social determinants. In: Blas E, Sivasankara Kurup A, editors. Equity, social determinates and public health programmes. Geneva, Switzerland: WHO; 2010. p. 219-241.

7. World Health Organization (WHO). Global tuberculosis control, epidemiology, strategy, financing. Geneva:WHO; 2009. (Cited 2013 July 10). Available at: http://www.who.int/tb/publications/global_ report/2009/en/index.html

8. World Health Organization (WHO). Global tuberculosis report. WHO; 2012. (Cited 2013 July 7). Available at: http://www.who.int/ tb/publications/global_report/gtbr12_main.pdf

9. Ministério da Saúde, Secretaria de Vigilância em Saúde. Apresentação padrão do Programa de Controle Nacional da Tuberculose. Brasília: Ministério da Saúde; 2013. (Cited 2013 July 9). Available at: http:// portalsaude.saude.gov.br/portalsaude/arquivos/pdf/2013/Mar/25/ apres_padrao_base_22_02_2013_site.pdf

10. Instituto Brasileiro de Geografia e Estatística (IBGE). Banco de dados: Cidades@ (Internet). Rio de Janeiro: IBGE; (Cited 2013 November 3) Available at: http://www.ibge.gov.br/cidadesat

11. Batista D. Aspectos epidemiológicos da tuberculose no Amazonas. Bol Oficina Sanit Panam 1953; 5:4333-4347.

12. Oliveira GP, Torrens AW, Bartholomay P, Barreira D. Tuberculosis in Brazil: last ten years analysis - 2001-2010. Braz J Infect Dis 2013; 17:218-233.

13. De Oliveira GP, Pinheiro RS, Coeli CM, Barreira D, Codenotti SB. Mortality information system for identifying underreported cases of tuberculosis in Brazil. Rev Bras Epidemiol 2012; 15:468-477.

14. Oliveira GP, Pinheiro RS, Coeli CM, Barreira D, Codenotti SB. Mortality information system for identifying underreported cases of tuberculosis in Brazil. Rev Bras Epidemiol 2012; 15:468-477.

15. Souza SL, Feitoza PV, Araújo JR, Andrade RV, Ferreira LC. Causes of death among patients with acquired immunodeficiency syndrome autopsied at the Tropical Medicine Foundation of Amazonas. Rev Soc Bras Med Trop 2008; 41:247-251.

16. Saraceni V, King BS, Cavalcante SC, Golub JE, Lauria LM, Moulton LH, et al. Tuberculosis as primary cause of death among AIDS cases in Rio de Janeiro, Brazil. Int J Tuberc Lung Dis 2008; 12:769-772.

17. Casseb J, Fonseca LA, Medeiros LA, Gonsalez CR, Lagonegro ER, Veiga AP, et al. Tuberculosis among HIV-1-infected subjects in a tertiary out-patient service in São Paulo city, Brazil. Rev Inst Med Trop Sao Paulo 2012; 54:257-259.

18. Quincó P, Bührer-Sékula S, Brandão W, Monte R, Leopoldina $\mathrm{SS}$, Saraceni V, et al. Increased sensitivity in the diagnosis of tuberculosis in HIV-positive patients through small membrane filter method of microscopy. J Clin Microbiol 2013; 51:2921-2925.

19. Brazilian Ministry of Health, South African Ministry of Health. Bill \& Melinda Gates Foundation, Amsterdam Institute for Global Health and Development organized. From data to scale-up: building the evidence base for new tuberculosis diagnostics. Meeting report. Kuala Lumpur, Malaysia; 13 November 2012. (Cited 2013 June 20) Available at: http://www.tbfaqs.org/wp-content/uploads/2013/05/ MEETING-REPORT-From-Data-to-Scale-Up-New-TB-Dx2.pdf

20. Ministério da Saúde, Secretaria-Executiva. Ministério da Saúde e municípios: juntos pelo acesso integral e de qualidade à saúde. 
$2^{\text {nd }}$ ed. Brasília: Ministério da Saúde; 2013. (Cited 2013 June 16). Available at: http://portalsaude.saude.gov.br/portalsaude/arquivos/ Revista_MS_WEB_21_jan.pdf

21. Garrido MS, Penna ML, Perez-Porcuna TM, de Souza AB, Marreiro LS, Albuquerque BC, et al. Factors associated with tuberculosis treatment default in an endemic area of the Brazilian Amazon: a case control-study. PLoS One 2012; 7:E39134.

22. Ministério da Saúde, Departamento de Atenção Básica. Cadernos de Atenção Básica 21. Brasília: Ministério da Saúde; 2013. (Cited 2013 June 16). Available at: http://portal.saude.gov.br/portal/ arquivos/pdf/adcd21.pdf

23. Ministério da Saúde, Departamento de Atenção Básica (DAB) (Internet). Brasília Ministério da Saúde; Histórico de Cobertura da Saúde da Família- Teto, credenciamento e implantação das estratégias de Agentes Comunitários de Saúde, Saúde da Família e Saúde Bucal (Cited 2013 July 9). Available at: http://dab.saude.gov. br/dab/historico_cobertura_sf/historico_cobertura_sf_relatorio. php
24. Pérez-Porcuna TM, Ascaso C, Ogusku MM, Abellana R, Malheiro A, Quinco P, et al. Evaluation of new strategies for the diagnosis of tuberculosis among pediatric contacts of tuberculosis patients. Pediatr Infect Dis J 2012; 31:e141.

25. Ministério da Saúde, Departamento de Vigilância Epidemiológica. Coordenação geral de laboratórios de saúde pública. Brasília: Ministério da Saúde; (Cited 2013 July 7). Available at: http://portal. saude.gov.br/portal/arquivos/pdf/rede_lab_front.pdf

26. Ministério da Saúde. Secretaria Executiva. Departamento de Informática do SUS-DATASUS. Gerenciador de ambiente laboratorial (GAL). Manual do usuário. Versão 1.0.7. Brasília: Ministério da Saúde; (Cited 2013 July 7). Available at: http:/gal.datasus.gov.br/ GAL/download/Manual_Operacao_Modulo_Usuario.pdf

27. Ministério da Saúde, Secretaria de Vigilância em Saúde. Tuberculose: alinhada com o social, afinada com a tecnologia. Bol Epidemiol 2013; p. 44. (Cited 2013 June 5). Available at: http:// portalsaude.saude.gov.br/portalsaude/arquivos/pdf/2013/Abr/10/ boletim2_2013_tb_web.pdf 